\title{
Employee Wellness Management Programme as a Strategy for Transforming the Public Service - A Case of the Department of Agriculture in Limpopo Province of South Africa
}

\author{
Dr Matshidiso Kanjere \\ Ms Kgomotlokoa Thaba \\ Ms Khomotso Makgato
}

University of Limpopo

\author{
Doi:10.5901/mjss.2014.v5n27p1286
}

\begin{abstract}
Public service transformation has been at the heart of government since 1994. Therefore, to ensure that transformation takes place at different government departments, a number of programmes were introduced. One of such programmes is Employee Health and Wellness programme. The main focus of this programme is to bring about changes in the wellbeing and the working environment in the departments so that service delivery, employees' health and productivity can be accelerated and improved. Thus, the Limpopo Department of Agriculture started the implementation of an Employee Health and Wellness program in 2001 in response to the government mandate which was brought about by the birth of new democracy. Since every important programme has to be evaluated, therefore this article reports on the evaluation that was conducted on the success of wellness programmes in combating absenteeism in the Limpopo Department of Agriculture. Absenteeism in most government departments is a serious problem that negatively affects the delivery of services. There are many cases of absenteeism which have varied causes. However, the focus of this article is on the effectiveness of wellness management programme on combating absenteeism, and addressing the challenges of absenteeism due to substance abuse in the public service. The findings indicated that absenteeism negatively affects service delivery in the public sector and that participants on these programmes are offered limited support by their supervisors. Supervisors tend to show negative tendencies towards the wellness management participants who show little progress in recovery. This article therefore recommends that wellness programmes have to be fully supported by the management of various organizations so that they can be successful. Departments should also develop strategies that can curb substance abuse amongst the employees.
\end{abstract}

Keywords: employees wellness programmes, absenteeism, substance abuse and public health

\section{Introduction}

Wellness programmes (WPs) are intervention strategies intended to promote the well-being of employees. They could be curative and preventative in nature. The purpose of introducing a wellness programme in an organisation is to create an awareness of wellness issues, to facilitate personal change and health management and to promote a healthy and supportive workplace (Sieberhagen, Pienaar and Els, 2011:2). Employee assistance programmes (EAPs) are programmes that cover the identification, assessment, monitoring, referral, counselling, and follow-up activities that aim at addressing employees' problems. These definitions of EAPs and EWPs make it clear that these two types of programmes address similar issues about employee wellness.

While the definitions and measures of health and wellbeing differ, there tend to be two prominent person related concepts that are often combined with a more societal level perspective. Bessinger (2006) defines wellness as a three dimensional concept:

a) Health and wellbeing can refer to the actual, physical and health of employees as defined by symptomology and epidemiological rates of physical illnesses and diseases

b) or can refer to mental, psychological or emotional aspects of employees as indicated by emotional states and epidemiological rates of mental illness and diseases,

c) in addition to these two person related dimensions are societal dimensions of health and wellbeing, such as alcoholism and drug abuse rates and their consequences.

For any organisation to achieve global competitiveness, healthy employees are vital and therefore an Employee Health and Wellness programme can play an important role by enabling employees to deal effectively with the changes and challenges in the personal and work life (Bessinger, 2006:1). Whereas the environment in which one functions is 
becoming increasingly demanding, the changes in the organisations continues to pose challenges and changes in the environment (Bessinger, 2006).

The culture of an organisation can have a direct impact on both the employee's and organisation's health. Literature shows that healthy employees play an important role in creating organisational cultures (Attridge 2005; McVivar 2003). By implementing wellness programmes, organisations can deal effectively with productivity demands (Mulvihill 2005). In doing so, companies are moving in the right direction by focusing more on improving health and managing absenteeism through policies and procedures (du Preez, 2010:1). High level of absenteeism due to substance dependency has a detrimental effect on the organisation's ability to perform well. Reduced worker productivity and increased absenteeism related to substance abuse complaints are commonly encountered within the work force (Edries et al. 2013). As only healthy employees can perform optimally, employee health and wellness should be a high priority (du Preez, 2010:1).

According to Babaita (2008), absenteeism globally is a costly problem which is being neglected by management. Employees with mental and emotional issues account for $70 \%$ of the reasons given for sick leave (Rabe 2001). According to Yende (2005:9), in the USA alone, absenteeism costs the country 40 billion dollars per year and the UK is also affected by huge financial losses due to absenteeism. The annual loss to the South African economy is in excess of R2 billion. In developing countries including Nigeria, the cost of absenteeism is not known making its cost effect undetermined. In the US, it is estimated that over 400 million person days are lost each year as a result of absenteeism. Studies further confirm that employees who test positively for drugs and alcohol at the workplace experience higher levels of absenteeism and use sick leave to a far greater extent than non-users. It is further reported that absenteeism amongst current users of cocaine and marijuana is 50\% higher that amongst non-users (Yende, 2005:9).

A focus on employee wellness benefits both the employees and the organisation. The benefit of health promotion programmes is not only to increase participants' health, but also to decrease the cost to the company through fewer instances of absenteeism (Anderson et al., 2009; Mills et al., 2007). They further state that the employers could determine the underlying cost of absenteeism by implementing EHW programmes. EHW would enable the organisation to identify the problem the individual employee is experiencing, take remedial action and save much needless expense. Even more importantly, it will show employees that the organisation cares about them.

The Limpopo Department of Agriculture started the implementation of an Employee Health and Wellness program since 2001 in response to the need of transformation of public service that the birth of South African democracy in 1994 has introduced. The main focus was to bring about changes in the wellbeing and the working environment in the department so that service delivery, employees' health and productivity could be accelerated and improved. Cases of absenteeism are in place with varied causes. Programmes to address absenteeism are in place; however substance dependency cases seem to have a lot more effect on absenteeism than other work related problems.

Thus a study was conducted at Limpopo Department of Agriculture in Capricorn District Municipality to evaluate the effectiveness of wellness management programme on absenteeism.

\section{Definition of Key Concepts}

\subsection{Wellness}

Wellness is a conscious and deliberate approach to an advanced state of physical, psychological, and spiritual health' (Ardell, 1985:38). Corbin and Pangrazi (2001:3) define wellness as a multidimensional state of being describing the existence of positive health in an individual as exemplified by quality of life and a sense of well-being.

\subsection{Wellness Management Programme (WMP)}

A wellness program is any program implemented by an employer to improve the health of its labor force. A good wellness program also helps individual employees to overcome specific health-related issues. According to the Strategic Framework, WMP covers the traditional areas which address the entire spectrum of psycho-social stressors in the workplace in order to enhance individual and organisational and ultimately productivity. It has the following priority areas: Employee Wellness Programme, Wellness Programme and Work Life Programme.

\subsection{Employee Assistance Programme}

Employee Assistance Programme refers to a programmatic intervention, usually at the level of the individual employee 
using behavioral science knowledge and methods for the recognition and control of certain work and non-work-related problems (Berridge and Copper, 1994:5).

\subsection{Absenteeism}

Absenteeism is defined as a specific employee's unavailability for work, when work is actually available for this specific employee due to illness or injury (Newburn and Lo, 2009). Absenteeism simply refers to the time an employee is not on the job during scheduled working hours, granted leave of absence holiday or vacation time (Babaita, 2008).

\subsection{Substance Abuse}

Substance Abuse is when a client's use of alcohol or another mood altering drug has undesired effects on his/her life or on the lives of others. The negative effects of the substance may involve impairment of physiological, psychological, social or occupational functioning (Chetty, 2011:11).

\section{Public Health Theory}

The theory underpinning this article is a Public Health Theory. The theory advocates health promotion which is "a process of enabling people to increase control over and to improve their health" River and Glanz (2005). The Public Health Theory also advocates for policies that support health promotion programmes that seeks to address health problems across multiple levels. According to this theory health promotion is the responsibility of governments, communities, organizations and individuals. Governments should ensure that there are programmes that prolong life and promote health. Hence, the employee wellness management programme was initiated by the South African government as a strategy to accelerate service delivery.

Governments engage in a number of innovative strategies that will ensure a healthy work force that is able to operate and deliver on its mandate. Thus, health issues are defined differently to include a number of social ailments which were previously not classified as such. Potvin, Gendron, Bilodeau and Chabot (2005: 592) state that public health is increasingly understood to be the permeation of health issues into the social realm; where a growing number of situations traditionally regarded as social problems are reinterpreted within a health framework. For an example, illicit drug use and alcoholism are reinterpreted within a health frame work.

\section{Literature Review}

Many employees and their families are negatively affected by drug and alcohol abuse. The abuses also affect job productivity and service delivery as they are projected in chronic absenteeism. Absenteeism has been described as the single largest source of lack of productivity in business and industry in the UK (Baker-McClearn et al., 2010:311). Ally (2009:14), in his survey indicated that employers cited increased absenteeism, reduced productivity, and increased healthcare costs as the consequences of employee substance abuse.

According to Terblanche (2012:230), employees and their dependents benefit from assistance provided by workplace programmes that manage their physical health and emotional wellbeing. Chronic health conditions such as substance abuse are some of the concerns that filter into the job environment and influence absenteeism, accidents and job productivity.

There are many causes of absenteeism and these include serious accidents and illness, low morale, poor working conditions, boredom on the job, lack of job satisfaction, inadequate leadership and supervision, personal problems (financial, marital, substance abuse, child care etc.), poor physical fitness, inadequate nutrition, transportation problems, the existence of income protection plans, provisions which continue income during periods of illness or accident, stress, workload and employee discontent with a collective bargaining process or results. A greater distinction should be made between absences for appropriate reasons such as illness and medical reasons, and absence for inappropriate reason such as being drunk (Babatia, 2008).

Several participants from Ally's (2009) survey agreed that substance dependency and abuse would hinder the levels of attendance and punctuality among staff members. Substance dependency was perceived to have negative effects on personal relationships, productivity, punctuality, attendance, health and safety. Every employee who is dependent on alcohol costs the company an extra quarter of the employee salary per year due to absenteeism, occupational accidents and loss of productivity (Yende, 2005:22). While substance abuse was viewed as an individual 
choice, the social environment was identified as a major contributing factor to the patterns of substance abuse and dependency among employees.

Steinmal et al. (in Yende, 2005) interviewed a sample of male alcoholics of which $67 \%$ were in employment. He found that each lost 86 working days a year due to absence, $67 \%$ of the sample was often late for work, $61 \%$ reported Monday morning absenteeism and $62 \%$ sometimes took alcohol at work.

In the United Kingdom (UK), The Confederation of British Industry (CBI) found that 'substance dependency' was the second largest cause of absence in the UK workforce (CBI, 2001a, 2001b). There is now recognition that social factors are critical to understanding quality of life (Putnam, 2000; Wilkinson, 2001). Economic and social sustainability cannot be achieved by technology and science alone. Attention needs to be given to human needs and differences. The Audit Commission and the Countryside Agency have become involved in the development of quality of life indicators and work focussed on quality of life enhancement. More specifically, relevant drivers can be identified in the several moves to establish healthy workplaces. The workplace is a key setting through which to improve health and reduce health inequalities (Department of Health, 1999).

While reducing or containing health care-related costs has been an important strategy for companies in the USA, this is not the only way that improved employee health might improve overall corporate performance. Greater gains may be experienced through the direct influence of positive employee health and well-being on individual or group productivity, improved quality of goods and services, greater creativity and innovation, enhanced resilience, and increased intellectual capacity. The challenges of measuring these gains, however, become immediately apparent. For example, the history of productivity measurement reveals different approaches for different jobs and industries. Few jobs actually produce objective counts of tasks (such as number of sales). White collar workers may only receive performance reviews once per year, often without any objective measure attached. The only commonly shared measure relates to absences and such data simply reveals the measurement dichotomy of 'on the job' or 'absent' and overlooks gradations of impairment of workers who are present. As Riedel, Lynch, Hymel and Peterson (2001) suggest, in both the business and the research sectors there is a critical need to better quantify the value produced by employees.

Work and organizational factors can have both positive and negative impacts on the health and well-being of workers. Combining health and organizational factors may contribute to increasing the health and wellness of an organization's workers' productivity (Babatia 2008). According to Yende (2005:36), an EAP may be used as a strategic tool which is an essential business driver and may be used in the development and retention of staff, thus reducing absenteeism in workplaces. EAP is recognized as a valuable asset to business and industry in reducing absenteeism, workplace accidents, substance abuse and loss of productivity.

Monitoring absence and supporting health and wellbeing improves productivity and lowers absence levels and may reduce the length of the current and subsequent periods of absence (Baker-McClearn, 2010:312). Several large organisations have implemented proactive health and absence management policies intended to empower employees to take responsibility of their own health and wellbeing. Research from Scandinavia supports this idea by arguing that by being proactive, economic benefits are realized in a form of increased performance and productivity and a reduction of absence levels (Van Amelsvoort et al. 2006).

Reynolds, Lehman, and Bennett (2008) assert that employee's "reluctance to voluntarily seek help with regard to their substance abuse issues poses a major problem for EAPs". They suggest that this can perhaps be attributed to the employees "ignorance of the EAP services available or to the lack of trust of EAPs". Other reasons could include the social stigma of addiction, self-concealment, and denial (Reynolds et al., 2008). According to Malliarakis and Lucey (2007), issues such as substance abuse, dependency and addiction are laden with emotion. They suggest that it is common for individuals to initially react to such issues prior to responding to them cognitively; "denial is a hallmark of the disease of addiction" (Malliarakis \& Lucey, 2007:368).

\section{Research Methodology}

Qualitative research design was used to conduct the investigation. The primary goal of using this approach was to define, describe and understand the phenomena in its natural environment. Leedy and Ormrod (2014: 142) maintain that a qualitative research approach provide a means through which a researcher can judge the effectiveness of a particular policies, practices or innovations.

\subsection{Aim of the Study}

The aim of the study was to evaluate the effectiveness of wellness management programmes on absenteeism due to 
substance abuse in order to determine as to whether the wellness management programmes were effective in decreasing absenteeism in the department of Agriculture in Capricorn District in Limpopo Province. Statistics on EAP for 2011/2012 in the Limpopo Department of Agriculture have shown that amongst all the problems of various natures, there seems to be a high rate of absenteeism among employees. While absenteeism and substance abuse are recorded separately, the study focused on absenteeism caused by substance abuse.

\subsection{Objectives}

The primary objective of the study was:

1. To evaluate the effectiveness of the wellness management programme in addressing the challenges of absenteeism due to substance abuse in the public service.

2. To assess the benefits of both the employers and employee from the wellness management programme

3. To explore the other intervention strategies that can help in reducing the rate of absenteeism in the public service.

\subsection{Research Questions}

The democratic government of the Republic of South Africa passed legislation on employee social issues, which led to the implementation of workplace wellness programmes, but despite the implementation of these programmes, employees in the Limpopo Province continue to be absent from work. Therefore, the following research questions were posed:

1. How effective are wellness management programmes in addressing the challenges of absenteeism in the Department of Agriculture?

2. What are the benefits derived from the wellness management programmes to both the employers and the employees?

3. What are other intervention strategies that can help in reducing the rate of absenteeism in the Department of Agriculture?

\section{Data Collection}

Data was collected from two different units in the department. The participants in the study were selected on the basis of having been on the wellness management programmes. Thus, purposive sampling was used as selection methods of participants in the study. Participants comprised of employees, supervisors who are co-ordinating the programmes, as well as supervisors in the selected units. Interviews were conducted with the participants as a means of collecting data; and their responses were recorded.

Eighty -percent of the participants who were interviewed indicated that their absenteeism was induced by substance abuse. One participant stated that he abuses both alcohol and glue. The other participant in the study indicated that alcohol abuse was a common phenomenon amongst the referrals to wellness management programmes. Participant $C$ stated that he absents himself for the whole week, especially after pay day and the other Participant $D$ stated that he frequently absent himself from work on Mondays.

Sixty-seven participants believe that the Wellness Management Programmes are beneficial and that they can yield fruits in the long-term. However, Participant $\mathrm{E}$ indicated that he had not attended to his proactive programme. He indicated that even though the programme is good, many people do not use it because is voluntary and that it is not well coordinated in the district.

Participant $\mathrm{F}$ indicated that his change was slow at first because of personal denial; he was denying the fact that he was an alcoholic. His supervisor arranged that he attend a rehabilitation sessions with South African National Council on Alcoholism (SANCA). He indicated that the sessions that he attended at SANCA had equipped him and motivated him to recover his self-esteem.

Supervisor A stated that some employees relapse after some time and that the problem of absenteeism persists. He said that on average employees absent themselves for a period of two days in a week and they thus work for only three days. He said that he expected the programme to bring about visible change and immediate results, but was disappointed to find that employees continue to be absent even after rehabilitation and intervention. According to him, the programme does not get the attention it deserves from the management. He stated that his role in the programme was to influence referrals and to support employees.

Supervisor B believes that the Wellness Management Programme helps the employees to maintain their moral 
code of conduct in the workplace; and that it promotes productivity. He was also of the opinion that the employer was also benefitting from the success of the programme. He recommended that the award system be introduced to motivate people to do well in the work place.

\section{Data Analysis}

$80 \%$ of the respondents agreed that the programme was yielding positive results and that it was effective. $20 \%$ stated that the programme was slow and therefore not yielding results as expected.

It can be deduced from the data presented that employees are positive about the wellness programme as opposed to the supervisors who are expecting immediate and visible results. Nevertheless, it was agreed that the programme has benefits for both the employers and employees.

Wellness Management Programmes can contribute to high production if all employees can be at work and do their part. Some of the service delivery problems are escalated by the fact that employees are not at work at all times.

Management should play an active role in supporting employees who are on the programme and also introduce some incentives for those who are doing well.

\section{Conclusions and Recommendations}

The study concluded that wellness management programmes are necessary in a work place and that they can be used to combat absenteeism. However, management support has to be increased so that the programmes can yield more results for the department. Some supervisors want to see immediate results and thus put pressure on the participants. Supervisors should know that habits are difficult to break and that a relapse should be expected along the way to recovery. On the other hand employees who are on the programme be encouraged to take responsibility of their own recovery. They should be made aware of the effect that their absence from work is having on the service delivery. It should nevertheless be noted that the programme together with the other management strategies can help transform the service delivery landscape.

\section{References}

Ally, S. 2009. Substance Dependency and Abuse within the Workplace: A Case Study Exploring Supervisors' Experiences and Perceptions of Employee Substance Dependence and Abuse. University of KwaZulu Natal: South Africa.

Attridge, M. 2005. The Business Case for the Integration of Employee Assistance: Worklife and Business Services. Journal of Workplace Behavioural Health. 20(1):31-55.

Babaita, I.S. 2008. The effect and measurement of workplace absenteeism in the banking industry in Nigeria. LIJOMASS. 1(1).

Baker-McClearn, D., Greasley, K., Dale, J. and Griffith, F. 2010. Absence Management and Presenteeism: The pressures of employees to attend work and the impact of attendance on performance. Human Resource Management Journal 20(3):311-328.

Bessinger, M.E. 2006. The development of a model of an Employee Wellness Programme for a fast moving consumer goods organisation. Faculty of Economic and Management Sciences: University of Pretoria.

Creswell, J.W. 2009. Research design: A qualitative, quantitative, and mixed method approaches. Thousand Oaks: SAGE Publications.

Denzin, N. and Lincoln, Y. 1998. Strategies of Qualitative Enquiry. Thousand Oaks: SAGE Publications.

De Vos, A.S., Strydom, H., Fouché, C.B. and Delport, C.S.L. 2005. Qualitative data analysis and interpretation, in Research at grass roots: for the social sciences and human service professions. $3^{\text {rd }}$ ed. Pretoria: Van Schaik.

Du Preez, H. 2010. The impact of corporate wellness program on employee wellness, motivation and absenteeism. University of Pretoria: South Africa.

Edries, N., Jelsma, J. and Maart, S. 2013. The impact of an employee wellness programme in clothing / textile manufacturing companies: A randomised controlled trial. BMC Public Health 13 (25). <http://www.biomedcentral.com/1471-2458/13/25> (accessed 2013 October 07).

Department of Public Service and Administration. 2008. Employee Health and Wellness Strategic Framework for the Public Service. South Africa.

Fossey, E., Harvey, C., McDermott, F. and Davidson, L. 2002. Understanding and evaluating qualitative research. Australian and New Zealand Journal of Psychiatry, 36:717-732.

Griffin, D. [Sa]. What is an Employee Wellness Program? http://smallbusiness.chron.com/employeewellness.p1349.html.

Grinnell, R.M. 2001. Social work research and evaluation: quantitative \& qualitative approaches. Belmont: Brooks/Cole.

Leedy, P. D. and Ormrod, J. E. (2014). Practical Research Planning and Design. 10th Edition. Harlow EssexPearson.

Malliarakis, K.D. and Lucey, P. 2007. Social determinates of health: Focus on substance use and abuse. Nursing Economics 25(6):368371.

McVivar, A. (2003). Workplace stress in Nursing: A Literature Review. Journal of Advanced Nursing 44(6): 633-642. 
Milani R.V. and Lavie C.J. 2009. Impact of worksite wellness intervention on cardiac risk factors and one-year health care costs. American Journal of Cardiology 104(10):1389-1392.

Mouton, J. 1998. Basic concepts in the methodology of the social science research. Pretoria: HRSC.

Mulvihill, M.D. 2005. Health and Productivity Management. Journal of workplace Behavioural Health 20(1):57-66.

Naidoo, A.V., and Jano, R. 2003. The role of EAPs the SA context. The Social Work Practitioner-Researcher: A Journal on the Application of Research in Practice 15(2):113-127.

Neuman, W.L. 2000. Social work methods: qualitative and quantitative approaches. London: Allyn \& Bacon.

Patton, M.Q.1990. Qualitative research and evaluation methods. London: Sage Publications.

Reynolds, G.S., Lehman, W.E.K. and Bennett, J.B. 2008. Psychosocial correlates of the perceived stigma of problem drinking in the workplace. Journal of Primary Prevention 29(4):341-357.

Riedel, J.E., Lynch, W., Baase, C., Hymel, P. and Peterson, K.W. 2001. The effect of disease prevention and health promotion on workplace productivity: A literature review. American Journal of Health Promotion 15:167-191.

River, B and Glanz, K (2005). Theory at a Glance: A Guide for Health Promotion Practice. 2 ${ }^{\text {nd }}$ Edition. http://www.cancer.gov/E0C3c96F2CFC-490F-A593

Rubin, A. and Babie, E. 1995. Research methods for social work. Los Angeles: Wadsworth.

Potvin, L., Gendron, S., Bilodeau, A and Chabot, P( 2005) Integrating Social Theory into Public Health Practice. American Journal of Public Health. 95(4):591-595

Sieberhagen, C., Pienaar, J. and Els, C. 2011. Management of Employee Wellness in South Africa: Employer, Service Provider and Union Representatives. SA Journal of Human Resource Management 9(1): 305.

Terblanche, L.S. 1992. The state of the art of EAPs in SA: A critical analysis. In R. P. Maiden (Ed.), Employee assistance programmes in South Africa 17-28.

Terblanche, L. and Pillay, R. 2012. Caring for South Africa' public sector employees in the workplace: A study of Employee Assistance and HIVIAIDS Workplace Programmes. Journal of Human Ecology 39(3):229-239.

Yegis, B.L. and Weinbach, R.W. 2002. Research methods for social workers. Boston: Allyn and Bacon.

Yende, PM. 2005. Utilizing Employee Assistance Programme in the Workplace. Faculty of Management. University of Johannesburg: Jo 